\title{
Technology and Application of Humidity Control under High Humidity Environment
}

\author{
Miao Lou', Xudong Liao ${ }^{\mathrm{b}}$, Yingjun Huang ${ }^{\mathrm{c}}$, Liangrui Fu ${ }^{\mathrm{d}}$, Baoliang Zhu' ${ }^{\mathrm{e}}$, Bo Lif \\ The North-West Institute of Nuclear Technology, Xi'an 710024, China \\ aloumiao531@163.com, ${ }^{b}$ Ixd_email@126.com, ${ }^{c}$ huangjun888500@163.com, ${ }^{d} 511851318 @ q q . c o m$, \\ 'hyj888500@163.com, flibo08c@163.com
}

Keywords: Environment Humidity, Dehumidification, Measurement and Control

\begin{abstract}
According to previous monitoring data, the high humidity environment of certain is $30 \% \mathrm{RH} \sim 40 \% \mathrm{RH}$ when well ventilated. After the project is plugged, the temperature is generally about $18^{\circ} \mathrm{C}$, and the humidity rises quickly to about $80 \% \mathrm{RH}$ within 2 days and gradually increases to $90 \% \mathrm{RH}$ in next 7 to 10 days, then remaining unchanged. In order to reduce the environmental humidity after backfilling and plugging the tunnel, and control the ambient humidity below 45\%RH. This paper describes a humidity control system which could achieve the isolation of the built-in dehumidification system with outside and the dehumidification with a cycle of dry and wet air in the cavern through the remote controlling. The system could accurately measure the volume of condensate water that collected automatically, and discharged the water into the multiple isolation protection deeper hole. The system accumulated dehumidified water is about $3236 \mathrm{~kg}$ in 24 days, and the humidity of the cavern can be effectively controlled at around 30\%RH.
\end{abstract}

\section{Introduction}

Based on former monitoring data, some high environment humidity is $30 \% \mathrm{RH} \sim 40 \% \mathrm{RH}$ under the circumstance of ventilation and temperature is normal about $18^{\circ} \mathrm{C}$ after the close. The humidity rise fast after slow with around $80 \% \mathrm{RH}$ in $2 \mathrm{~d}$, after that it rises to above $90 \% \mathrm{RH}$ and maintains in stable. In order to provide low humidity environment, environment humidity must be lowered after the close with 45\%RH environment humidity or below. This article introduces one humidity control system, which can control the environment humidity effectively to meet the engineering requirements.

\section{System Design}

\subsection{System Composition}

Temperature Control System is composed of dehumidifier, intake exhaustion system, drainage system and remote measurement control system (the configuration refers to Fig.1). The dehumidifier is in charge of air condensation and dehumidification to discharge dry air; intake exhaustion system is in charge of the internal air circulation of whole confined space; drainage 
system is in charge of air condensate water collecting; remote measurement control system is in charge of run monitoring for whole system.

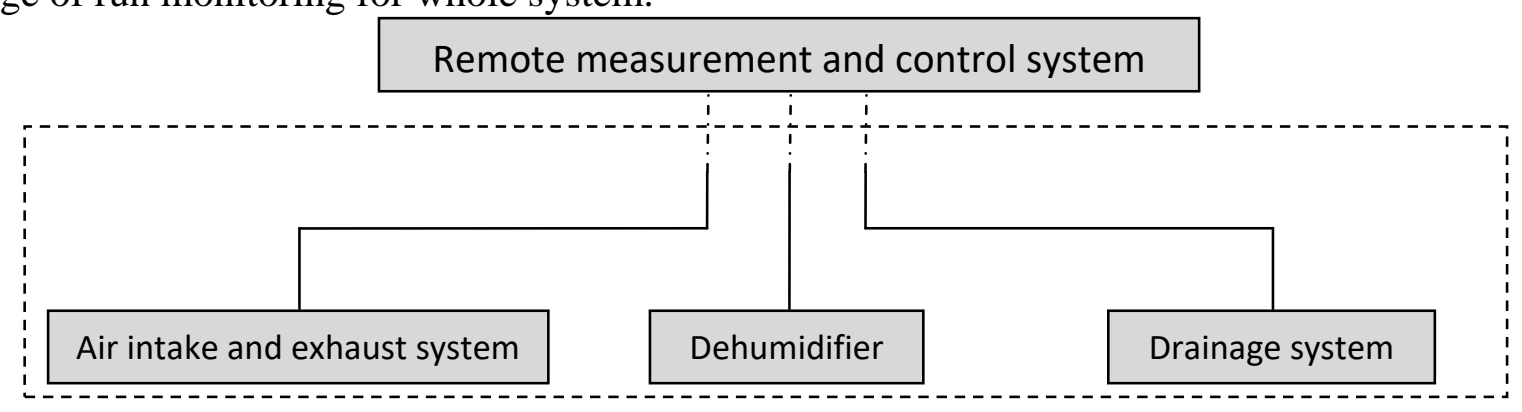

Fig.1 Temperature Control System

\subsection{Design of Measurement and Control System}

Measurement and Control System is placed outside the confined place to control the valve of dehumidifier and storage hole and monitor the humiture of air vent, liquid level of water tank and photography of dehumidification room as well as comprehensive evaluation of the dehumidification and protective effect. Method of 485 bus local networking and long-distance optical fiber data transmission is used; its system structure refers to Fig.2. Dehumidifier is equipped with 485 bus communication interface, so choose the sensor module with 485 communication function to connect with dehumidifier via 485 bus to achieve distributed data transmission and interaction. Use fiber transmission method to transmit the collected signal by 485 bus to measurement control site via fiber transmission, then decode conversion to present on the computer.

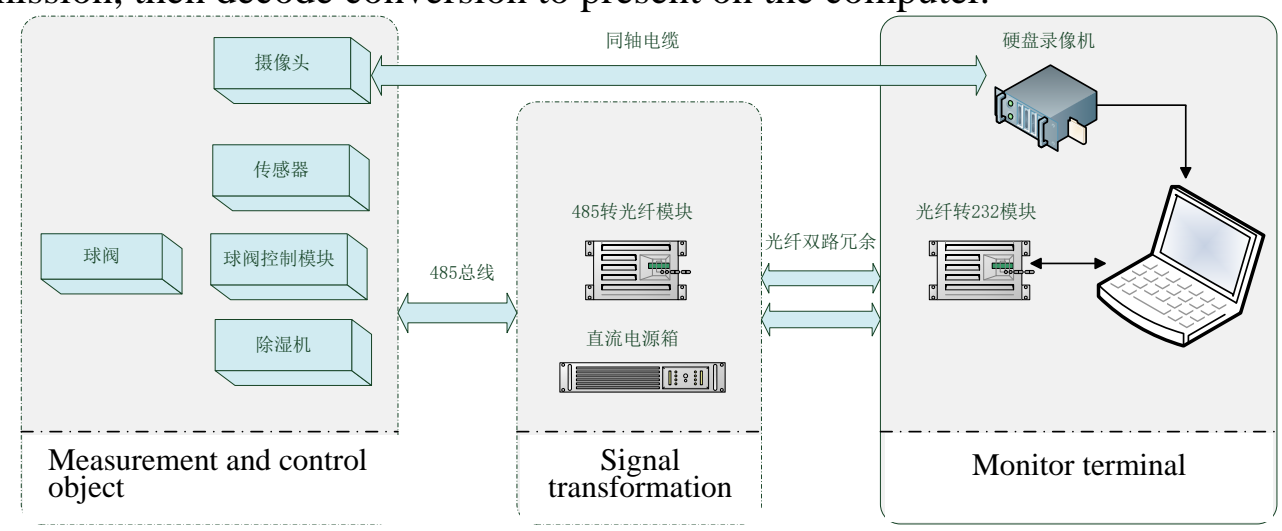

Fig.2 Measurement and Control System

\subsection{Software Design}

Software of host computer is written with C\# language, cooperated with Winform framework and Measure studio interface library released by NI corporation. The main interface refers to Fig.3 with left, middle and right 3 function areas. The left is responsible for the allocation and connection of serial interface and mode switch of software work; the middle is the main display panel to display the real-time humiture; the right is manual mode area to control the dehumidifier and ball valve. Besides, two auxiliary display panels are quipped to map the data curve in real time and set the dehumidifier configuration. 


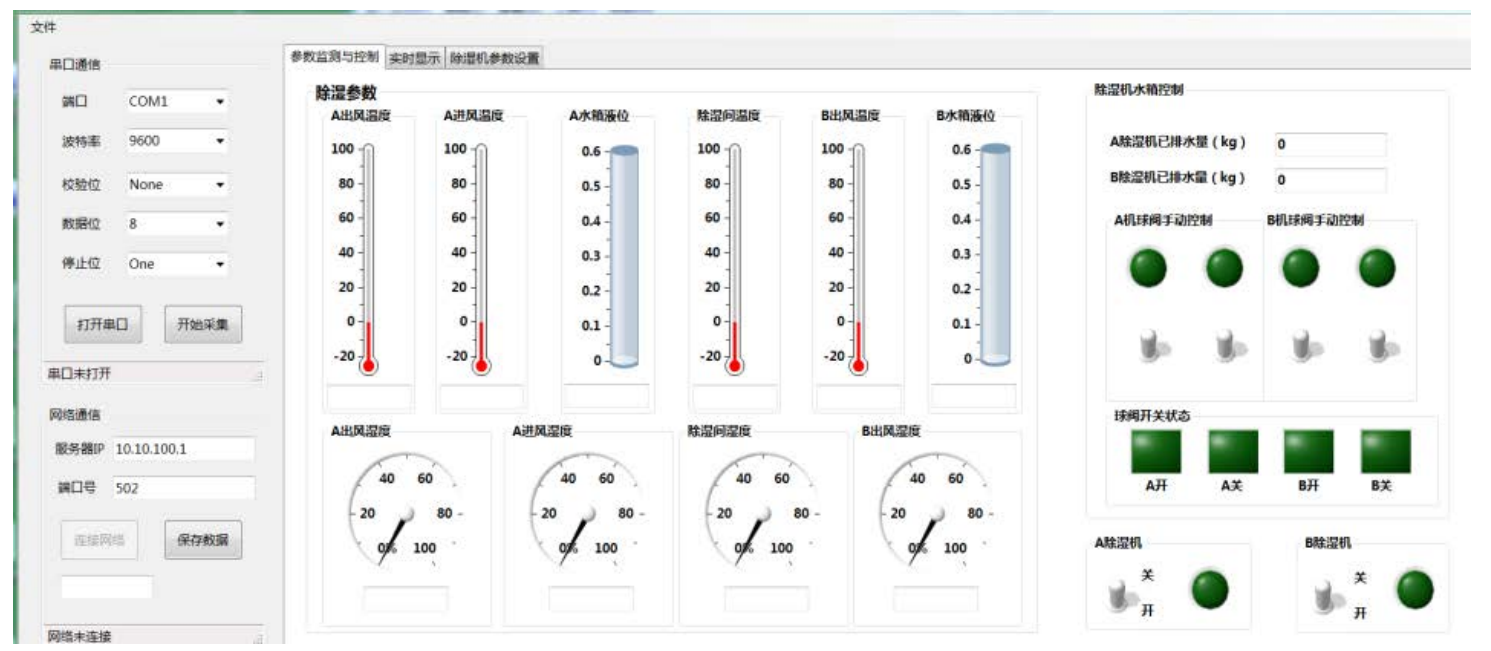

Fig.3 Software of host computer

\section{Data Analysis}

\subsection{Environment Humidity Analysis}

After the humidity control system runs, the indoor moisture will be cooled and dehumidified with the decline of environment humidity. Meanwhile, the moisture in the wall will replenish the indoor air constantly. The 7 days monitoring data of environment humidity can refer to the Fig.4. The environment humidity decreases gradually from $75 \% \mathrm{RH}$ to $40 \% \mathrm{RH}$ after the system runs and environment humidity rises to $73 \% \mathrm{RH}$ after the system stops. During the system running, the operating mode of dehumidification and defrost of dehumidifier will affect the environment humidity fluctuation. The environment humidity decreases under dehumidification, while increase under defrost. With the long system running, the environment humidity value becomes lower and lower with slow increase of humidity and top $65 \% \mathrm{RH}$. It shows the water content of the wall decreases gradually and also the speed of water supplement. The longer running time of humidity control system causes lower controlled environment humidity value. No great influence on environment humidity under system running. The environment temperature is $20 \sim 23^{\circ} \mathrm{C}$ under running and $20^{\circ} \mathrm{C}$ off running.

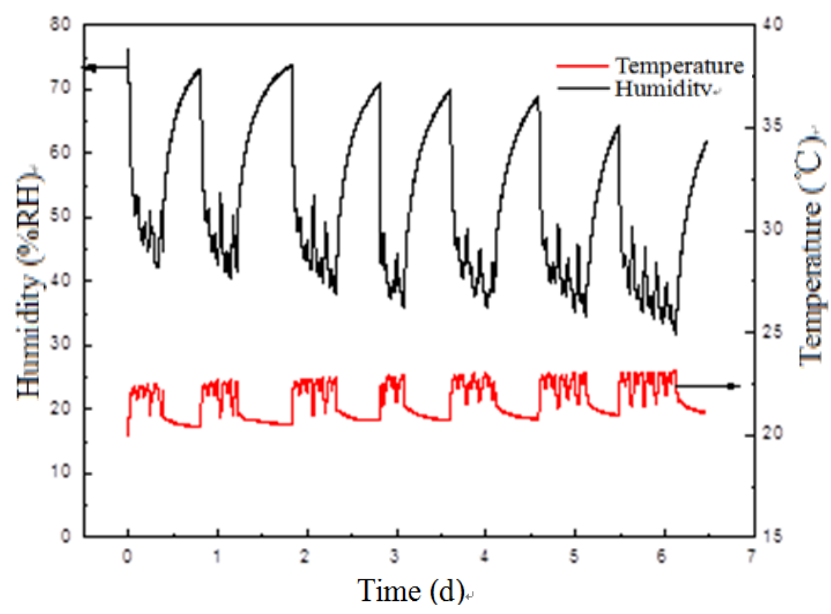

Fig.4 Monitoring data of environment humidity 
The rising data of environment humidity can basically represent the water supplement data of wall. Therefore, it concludes that the water seepage rate is slow after the first fast and lower environment humidity of confined space with fast wall water seepage rate and water supplement rate.

\subsection{Water Supplement Analysis}

The volume of confined space is $5000 \mathrm{~m}^{3}$ with measured temperature $22^{\circ} \mathrm{C}$ and density $\rho$ of $19.41 \mathrm{~g} / \mathrm{m} 3$ for saturated vapour, please refer to the design formula (1) of water content.

$$
\mathrm{Q}_{1}=\rho \mathrm{V} \psi
$$

$\rho$ - the density of saturated vapor for environment humidity, $\mathrm{g} / \mathrm{m}^{3}$;

$\mathrm{V}$-volume, $\mathrm{m}^{3}$;

$\psi$-humidity variation, \%RH.

Take the example of environment humidity decreases from $76 \% \mathrm{RH}$ to $30 \% \mathrm{RH}$, the air water content Q1 is $44.6 \mathrm{~kg}$ and measured dehydration is $3236 \mathrm{~kg}$, hence the water seepage in the wall is $3191.4 \mathrm{~kg}$.

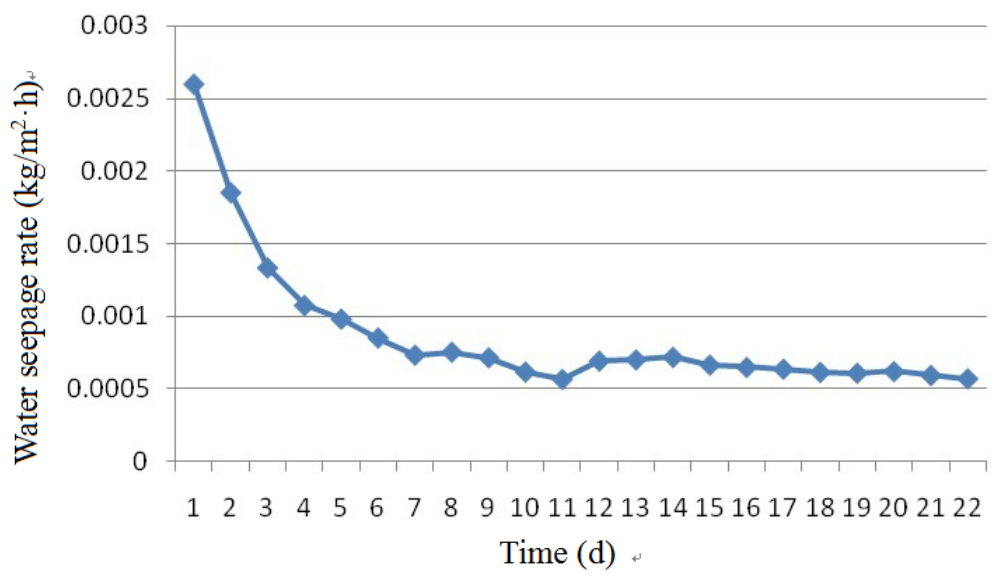

Fig.5 After the power off of the humidity control system

After the power off of the humidity control system, the moisture of the wall will spread into the air of confined space. The superficial area of wall is $3661 \mathrm{~m}^{2}$, assumed the increased water content of environment humidity is the wall water supplement content and calculate, the daily average wall seepage rate between $45 \% \mathrm{RH}$ and $60 \% \mathrm{RH}$ of daily environment humidity in the detailed data Fig.5. During the humidity control, the wall seepage rate is on the decrease from $2.6 \times 10^{-3} \mathrm{~kg} / \mathrm{m}^{2} \cdot \mathrm{h}$ to $6.0 \times 10^{-4} \mathrm{~kg} / \mathrm{m}^{2} \cdot \mathrm{h}$ with one lower level of water seepage velocity.

\section{Conclusion}

(1) The humidity control system, composed of dehumidifier, intake exhaustion system, drainage system and remote measurement control system can control the environment humidity in the range of 30\%RH and offer the solutions to similar environment humidity establishment.

(2) Develop a remote dehumidification and monitor system with 485 bus distributed measurement and fiber self-healing network transmission method for data to accomplish long distance distributed measurement and control and provide standard solutions for environment measurement and control.

(3) After 24 running days of humidity control system, the accumulated dehydration of confine space air and wall is $3236 \mathrm{~kg}$ with $3191.4 \mathrm{~kg}$ wall water seepage. In the process of dehumidification, 
the wall water seepage rate is on the decrease from $2.6 \times 10^{-3} \mathrm{~kg} / \mathrm{m}^{2} \cdot \mathrm{h}$ to $6.0 \times 10^{-4} \mathrm{~kg} / \mathrm{m}^{2} \cdot \mathrm{h}$.

\section{References}

[1] Zhang lizhi. Dehumidifying Technology. BeiJing: Chemical Industry Press, 2005.

[2] Wang hai. Study on wet environment and control method of underground cavern construction period of hydropower station. SWJTU (Southwest Jiaotong University), 2014.

[3] Wei daixiao, Zheng lihong, Ma li. Design of dehumidification system for underground engineering. Refrigeration \& Air-Conditioning, 2011.

[4] Du wei. Dehumidification effect and design method of underground water station dehumidifier. Xi'an University of Architecture and Technology, 2014. 